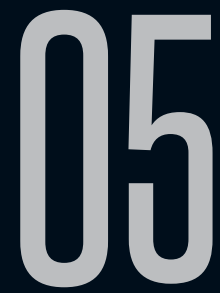

\title{
ALDEIA INSÓLITA
}

Maria Célia Martirani Bernardi Fantin

Recebido em 25 ago 2016. Maria Célia Martirani Bernardi Fantin: Doutora Aprovado em 27 set 2016. em Teoria Literária e Literatura Comparada pela USP; inscrita no Programa de Pós-Doutorado em Estudos Literários da UFPR; atuação no Mestrado em Estudos Literários UFPR (Literatura e Cinema); produção bibliográfica mais significativa: FANTIN, Maria Célia. The art of narrative in Alessandro Baricco. Edition №. 1. Germany: VDM Publishing House, May 2010; MARTIRANI, Maria Célia. Tradução: Alfabetos de Claudio Magris, Curitiba: Editora UFPR, 2012; MARTIRANI, Maria Célia. Lucida follia: saggi di letteratura dal boom ispanico ad Alessandro Baricco, Firenze: Franco Cesati Editore, 2016; participação no grupo de pesquisa: "Literatura e outras artes" do Programa de Pós-Graduação em Letras - Estudos Literários da UFPR; áreas de interesse: Literatura Comparada, Literatura e Cinema, Tradução, Estudos multiculturais; link de acesso ao CV_Lattes: http://lattes.cnpq. br/5033503866367056; http://www.escavador.com/ sobre/3320597/maria-celia-martirani-bernardifantin; email: mariacelia.martirani@gmail.com

Resumo: O presente estudo visa propor uma reflexão sobre as manifestações do fantástico, na obra Cenas da vida na aldeia, de Amós Oz (2009). Para tanto, tomamos como conceituação teórica básica as noções postuladas por Tzvetan Todorov em 
Introdução à literatura fantástica (2008), além do instigante ensaio de Francesco Orlando: Estatutos do sobrenatural na narrativa (2009), que amplia o leque de possibilidades de análise do gênero. Em nosso entendimento, a obra de Amós $\mathrm{Oz}$ não se filia à tradição das tendências fantásticas que lançam mão explicitamente do sobrenatural gótico ou fantasmagórico, mas explora ao máximo o que pode haver de inverossímil e inusitado nas contradições do próprio comportamento humano, fazendo irromper, ironicamente, o absurdo e o insólito na mais absoluta banalidade cotidiana.

Palavras-chave: Insólito; Fantástico; Amós Oz.

Abstract: This study aims to propose a reflection on the great manifestations in the book Scenes of village life, Amos Oz (2009). Therefore, we take as basic theoretical concepts the ideas postulated by Tzvetan Todorov in Introduction to fantastic literature, in addition to thought-provoking essay by Francesco Orlando Supernatural statutes in the narrative (2009), which expands the range of gender analysis possibilities. In our view, the work of Amos $\mathrm{Oz}$ is not affiliated to the tradition of fantastic trends that throw hand explicitly Gothic or Supernatural, but makes the most of what could be the unlikely and unusual in the contradictions of human behavior itself, making break, ironically the absurd and the unusual in absolute everyday banality.

Key-words: Absurd; Fantastic; Amós Oz.

A aldeia de Tel llan, próxima a Tel Aviv, surge em Cenas da vida na aldeia, de Amós Oz (2009), como um tópos que, antes de tudo, pretende se configurar como um daqueles locus amoenus descritos nos estudos de literatura medieval dedicados à recorrência das chamadas "paisagens ideais". 
É dessa maneira que esta aldeia de Oz se enquadra, a princípio, perfeitamente, nas descrições propostas, por exemplo, por Ernst Robert Curtius em Literatura Européia e Idade Média Latina. Seriam elementos essenciais dos "lugares amenos" a presença de árvores (uma ou várias), bosques, campinas, fontes de regatos, com possíveis variantes como canto dos pássaros, flores, sopros de brisa. É também desses cenários cantados por vários poetas da antiguidade clássica (Teócrito, Virgílio, Petrônio e tantos outros) que surgem muitos dos temas caros à poesia pastoril e arcádica (1996, p.254-258).

Os desdobramentos desses topos literários, sobretudo a partir da épica filosófica de fins do século XVII, passarão a assumir múltiplas formas em suas descrições do paraíso terrestre. Daí por que, nas palavras de Alain de Lille, "a residência da Natureza que oferece o máximo de beleza natural" seja o "lugar dos lugares", cujas delícias são enriquecidas com especiarias, bálsamo, mel, vinho, cedros e abelhas, além de ornatos mitológicos (1996, p.256).

Assim é que a aldeia aqui representada vem descrita, logo às primeiras páginas, com toda a exuberância da natureza dadivosa, como uma das mais belas paisagens de Israel, um "lugar dos lugares":

É lindo este lugar de vocês, senhor Tselkin! Espantoso! É a verdadeira Provence do Estado de Israel. Qual! Provence! Toscana! E essa sua paisagem! O bosque! Os vinhedos! Tel Ilan é simplesmente a aldeia mais encantadora de todo esse Estado tão levantino. Muito bonito! (OZ, 2009, p.9)

Desculpe! Aqui nesta sua linda varanda não dá para sentir como o dia está quente. Hoje está 
muito quente. Muito! E, no entanto, apesar do calor intenso - assim mesmo este lugar é encantador! Tel Ilan é sem dúvida a aldeia mais bonita do país! Provence! Não Provence! Toscana! Florestas! Vinhedos! Casas campestres de cem anos atrás, telhados vermelhos e ciprestes tão altos! (OZ, 2009, p.14)

Mas o que se esconderia nas sombras dos bosques, nos entremeios da paisagem generosa e complacente dessa espécie de ordem cósmica ancestral?

Como são os veios, os sulcos ocultos debaixo da pele intacta desse resistente ser-aldeia, tão bem personificado pelas vozes que a narram?

A aldeia era antiga e sonolenta, uma aldeia de mais de cem anos, com árvores grossas e telhados vermelhos e pequenas propriedades agrícolas, muitas das quais já se haviam transformado em tabernas que vendiam vinhos fabricados em adegas caseiras, azeitonas apimentadas, queijos feitos em casa, condimentos exóticos, frutas raras e trabalhos de macramê. (OZ, 2009, p.47)

De fato, o que constataremos, no curso da narrativa, é que o irretocável desse tópos assim idealizado se configura apenas para servir como cenário, para que nele se instaure, por meio de rupturas e contrastes, o inusitado, o estranho, o insólito. Melhor dizendo, cada uma das cenas que compõem o todo da obra sugere algo de impalpável, o que jaz subjacente à aparência de vida rotineira e tranquila, que carrega o puro ar local com o peso do que parece viver sob constante ameaça. Aliás, o universo alegórico que aqui se propõe, tangenciando situações, às vezes absurdas, kafkianas 
ou que configuram o limite da exacerbação da espera, como em algumas narrativas de Dino Buzzati ${ }^{1}$, não poderia deixar de remeter - ainda que indiretamente - ao contexto dos eternos conflitos entre palestinos e israelenses.

Sabe-se que, hoje, um dos autores israelenses mais conhecidos por suas iniciativas pacifistas é Amós Oz, detentor do Prêmio da Paz da Feira do Livro de Frankfurt. Sua postura crítica, antimilitarista e conciliadora, alinhada, por exemplo, a de alguns intelectuais e cineastas do porte de Amos Gitai (Kippur, 2000) e Eran Riklis (Lemon Tree, 2008), entre outros, rendem-no, em boa medida, persona non grata em sua própria terra natal.

É claro, então, que as amenidades da aldeia idealizada como lugar paradisíaco passarão, necessariamente, pelo processo de deterioração, em que nada ou ninguém se mantém intacto, já que, diante das guerras constantes do Oriente Médio, a vida real é sempre turbulenta e amedrontadora. Embora seja muito compreensível que o autor reitere - em entrevistas concedidas mundo afora que não faz uso da ficção com o propósito explícito de retratar a realidade, já que a literatura não pode ser refém do que Carlos Fuentes, por exemplo, denominou como o "aprisionamento das grades do real"2, evidencia-se, nesta antologia, a transfiguração de espaços e situações que remetem, inevitavelmente ao absurdo das catástrofes que vivemos todos os dias na contemporaneidade. A

1 Referimo-nos aqui especificamente ao romance $O$ deserto dos tártaros (1984) do famoso autor italiano, em que o protagonista Giovanni Drogo, militar de carreira, designado a viver em uma fortaleza, preparando-se para o ataque dos tártaros, acaba por ver toda sua vida desperdiçada, numa longa e torturante espera.

2 A propósito, gostaríamos de remeter à obra Geografia do romance (2007) de Carlos Fuentes, em que o autor reitera a urgência de exorcizar as mais que conhecidas bruxas que assombraram os escritores de sua geração, as rígidas exigências do cânone realista: realismo x fantasia; nacionalismo x cosmopolitismo; compromisso x formalismo. 
esse respeito, vale conferir o que se afirma em Sensação de perda que mobiliza é tema de livro de Amós Oz, de Ubiratan Brasil, de 0 Estado de S. Paulo, de 24 de outubro de 2009:

Tel Ilan, o espaço físico de Cenas da Vida na Aldeia, é um local fictício, que se soma agora à farta tradição literária de cidades imaginárias, mas Amós Oz insiste em afirmar que não utiliza a ficção para retratar a atualidade - ainda que os habitantes de seus contos tragam vestígios de pessoas com quem convive e o espaço físico se assemelhe a diversos kibutz israelenses, o escritor é enfático: essas páginas contam apenas histórias. Eterno candidato ao prêmio Nobel de Literatura, Oz prefere militar pela paz entre palestinos e israelenses em artigos ácidos, que não poupam nenhum governo. "O final do conflito depende de nossa atitude", afirma ele ao Estado, em um inglês manso, preciso, mas carregado de determinação". (2009, disponível em: http://cultura. estadao.com.br/noticias/geral,sensacao-de-perdaque-mobiliza-e-tema-de-livro-de-amos-oz,455810 acesso em: 10-agosto-2016)

Seria muito redutor tentar classificar todo engenho literário de Amós Oz como o de mera filiação à vertente da literatura conhecida como fantástica. Mas há que se reconhecer que, nessas cenas de vida na aldeia, a força e a complexidade do narrar estão justamente nas rupturas com a ideia de perfeição e de bom acabamento do locus amoenus, a partir da escolha de uma série de elementos que compõem o que se vem estudando na teoria literária como "configurações do insólito".

A obra Introdução à Literatura Fantástica, de Tzvetan Todorov (2008), é fundamental quando se pretende tratar desse tema. Seu mérito foi o de formular uma definição do gênero a partir da 
contribuição de vários teóricos, tais como Vladimir Sergueievitch Soloviov, Montague Rhodes James e dos especialistas franceses Castex, Caillois e Vax.

Com efeito, por exemplo, no entendimento do escritor francês Roger Callois, retomado por Todorov, a chave de entrada para a compreensão desse gênero está, precisamente, no conceito de ruptura enquanto um escândalo da racionalidade, uma laceração, uma irrupção insólita, quase insuportável, no mundo da realidade:

O fantástico é, assim, ruptura da ordem reconhecida, irrupção do inadmissível dentro da inalterável legalidade cotidiana, e não substituição total de um universo real por um exclusivamente fantasioso. O fantástico significa violação de uma regularidade imutável [...] 0 procedimento essencial do fantástico é a aparição: é o que não pode aparecer mas aparece, em um ponto e instante precisos, no coração de um universo perfeitamente peculiar em que se pensava, sem razão, que o mistério tivesse sido eternamente banido. Tudo parece como hoje e como ontem: tranquilo, banal, sem nada de insólito, e eis que, ou insinuando-se lentamente, ou surgindo de súbito, se manifesta o inadmissível. (Apud CESERANI, 1996, p.47)

Embora a obra de Todorov tenha se tornado referência obrigatória a quem queira se dedicar ao tema, há outras possibilidades de análise, revendo os postulados do famoso linguista búlgaro. É o que propõe, por exemplo, o instigante ensaio de Francesco Orlando: "Estatutos do sobrenatural na narrativa" (2009), que amplia o leque de possibilidades de análise do gênero, trazendo à luz uma teorização bastante original, buscando 
dialogar sutilmente com o conceito de "fantástico" elaborado por Todorov, que o entendia, em síntese, como "a hesitação diante do sobrenatural" (2009, p.254). Segundo Orlando, haveria muito mais a indagar a respeito, já que, após Freud, não faria mais sentido falar num irracional contraposto a uma racionalidade, sendo mais adequado falar em racionalidades distintas, mais ou menos tolerantes ou exigentes. Nesse tipo de abordagem, tende-se a levar em conta a "estrutura do inconsciente", que se mostraria fecunda para a teoria e a análise da literatura. Os estudos freudianos relevantes para tratar do fantástico ou do sobrenatural em literatura seriam, assim, os que se referem à "psicogênese do chiste", mais especificamente ao "gosto pelo absurdo" e pelos "jogos infantis com as palavras":

Qualquer que seja o motivo que leva a criança a iniciar esses jogos, creio que, em seu desenvolvimento posterior, ela própria desiste deles pela consciência de que são absurdos, divertindose algum tempo com eles devido à atração exercida pelo que é proibido pela razão. Usa agora tais jogos para se evadir da pressão da razão crítica. Muito mais poderosas são as restrições impostas à criança durante o processo educacional, quando se a introduz no pensamento lógico e na distinção entre o que é falso e verdadeiro na realidade; por essa razão a rebelião contra a compulsão da lógica e da realidade é profunda e duradoura. Mesmo o fenômeno da atividade imaginativa pode ser incluído nessa categoria. (FREUD, 1996, p.122-23)

Conforme o que propõe o estudioso italiano, o que mais interessa para o estudo em questão é a última linha em itálico do excerto extraído da obra de Freud, porque ela apresenta o mesmo 
prazer como origem da literatura em geral e da literatura com temas sobrenaturais em particular. Qualquer literatura requer a presença simultânea de instâncias opostas, e é em si mesma uma formação de compromisso: entre o real e o irreal.

Daí, porque, conclui que a "hesitação" proposta por Todorov é um conceito necessário, mas insuficiente, na medida em que, sob a temporalidade mais linear e lábil, suas soluções se tornam quase indiferentes:

Como designar o conceito, após a devida adequação? Levando em conta que o medo tem raízes numa profundidade onde é indelével o sopro do sobrenatural, não é preciso se preocupar senão com a tematização da dúvida: pouco importa o quanto se prolonga e como é solucionada. Burke (ao dizer que a escuridão é necessária para o terror, e a causa de seus poderes reside em "nossa ignorância das coisas") nos autoriza a falar num sobrenatural não de incerteza, e sim de ignorância. (ORLANDO, 2009, p.268)

Seja como for, tanto a hesitação todoroviana, quanto a ignorância de Burke ou a potência da atividade imaginativa preconizada por Freud, além da irrupção do inadmissível de Caillois podem ser encontrados em vários episódios da obra que aqui buscamos analisar. Entre eles, escolhemos o intitulado: "Os que cavam".

Neste flagrante de cena da aldeia, vivem numa extremidade de Tel Ilan o ex-deputado Pessach Kedem - 'um velho corcunda, alto, irascível e vingativo, de oitenta e seis anos, todo tendinoso e nodoso, áspero, a pele parecendo casca de oliveira' (OZ, 2009, p.43) -, sua filha Rachel Franco: 
[...] uma viúva bonita e bem cuidada com cerca de quarenta e seis anos, professora de literatura na escola da aldeia, sempre vestida com bom gosto, com largas saias em agradáveis tons pastel que combinavam com os de sua echarpe, calçando mesmo durante o trabalho na escola sapatos de salto alto e usando delicados brincos, e às vezes também um fino colar. $(O Z, 2009$, p.46)

Além dos dois, também, o jovem árabe Adel:

[...] um rapaz encurvado, tímido, mas também falastrão, que usava óculos pequenos demais, como se os tivesse tirado de um menino ou como se os preservasse desde sua infância. Esses óculos estavam amarrados num cordão e revelavam uma frequente tendência a embaçar na umidade, o que o obrigava a limpá-los e a tornar a limpá-los na manga da blusa que ele sempre vestia sobre amarfanhadas calças jeans. Em sua bochecha esquerda tinha uma covinha que lhe emprestava um ar infantil um pouco envergonhado. Só se barbeava no queixo e ao lado das orelhas, pois o resto de seu rosto ainda era liso e imberbe. $(\mathrm{OZ}$, 2009, p.61-62)

Há vários aspectos desta cena que chamam a atenção. O fluxo da narrativa corre com certa calmaria ao descrever, em minúcias, os personagens nela envolvidos, apresentando, inclusive, como interessante ponto de reflexão o fato de que, nessa casa, convivem israelenses e um estudante universitário árabe, em aparente harmonia.

Além de ajudar Rachel a limpar o jardim e contribuir com certas tarefas domésticas, Adel é o personagem escritor que se dirige para Tel Ilan, pois pretende escrever um livro em que as aldeias árabes 
e israelenses possam ser vistas comparativamente. Acredita ele que há, entre elas, no fundo, muitas semelhanças, para além de toda diversidade e hostilidade do ódio separatista. Logicamente, percebe-se no relato de Adel uma intencionalidade pacifista que, por si só, destoaria do contexto real que envolve aqueles países.

Mas o fator-surpresa, o elemento inesperado que acabará por gerar a verdadeira ruptura com a inalterabilidade cotidiana é o fato de que o velho, à noite, quando todos dormem, passa a ouvir estranhos rumores no subterrâneo da casa, que lembrariam sons de picaretas, como se alguém lhe escavasse a base.

No início, Rachel analisa a fala do pai como a de um homem ansioso e insone que sofreria de alucinações, decidindo, inclusive, aumentar-lhe a dose de sonífero. Mas, aos poucos, o aparente equilíbrio de uma vida regular e amena vai cedendo espaço ao barulho das escavações, que também será ouvido por Adel, para ao fim, correspondendo a uma inquietação anímica da professora, ser ouvido por ela.

A falta de retoque da cena está no final abrupto de uma ameaça, que se revela paulatina e joga o leitor na mesma espécie de abismo em que acabam sendo lançados os protagonistas.

Elementos recorrentes em todos os episódios da obra são os da invasão e os da dilacerante espera. Sejam hóspedes invasores, estranhas aparições, esperas vãs, cada uma das cenas permanece em aberto, inacabadas propositalmente, no contraponto necessário ao pano de fundo da aparente amenidade da aldeia idealizada. É por esse tipo de artifício, exatamente o de criar o inadmissível, interferindo na ordem comum das coisas, além do acento 
profundamente irônico, que a maestria de Amós Oz se reafirma, como hábil artesão de narrativas.

A fim de retratá-los fidedignamente, há detalhes preciosos na descrição dos habitantes do lugar. Uma série de tipos desfila, cada qual com suas idiossincrasias. São anunciados, abrindo cada um dos episódios, como: "Os que herdam, Os que são próximos, Os que cavam, Os que se perdem, Os que esperam, Os que são estranhos e Os que cantam".

No modo como são elencados, há o toque do coletivo que, embora foque o que cada um desses aldeões apresenta como marca própria e individual, jamais os distancia da noção de "espécie humana", da ampla comunidade a que pertencem. Nos títulos desses capítulos, o aldeão, por mais circunscrito que seja à sua aldeia, habitante de Tel Ilan, sai do particular ao geral, extrapola o regional e o provinciano e se identifica com os aldeões do universo, na grande aldeia humana global que herda, aproxima-se, cava, perde-se, espera, estranhase e canta. A problemática existencial dos seres da aldeia é, enfim, a mesma dos seres que habitam o mundo. Talvez, um pouco como o pequeno rio da aldeia pessoana de Alberto Caeiro comparado ao Tejo, que, embora aparentemente insignificante, vai desaguar nos rios do mundo, ou como as veredas do sertão de Rosa, caminhos e descaminhos da vastidão desse mesmo mundo...

Assim nos irmanamos, reconhecemo-nos e a literatura, ainda que reforçando particularidades, é capaz de ecoar amplos traços de nossa singular humanidade.

Importa também notar que a escolha por esse tipo de espaço ficcional não é, em nada, aleatório. Propositalmente, nos 
diversos episódios que compõem estas Cenas da Vida na Aldeia, o narrador investe ironicamente, de tal modo, no contraste entre o rural e o urbano, que o que se obtém, ao fim e ao cabo, é tão pueril, como alguns temas ingênuos, altamente idealizados, que costumavam frequentar certas composições infantis em bancos de escolas de outrora. E o que resulta desse tipo de procedimento é o da sensação de profundo estranhamento, já que é praticamente impossível imaginar lugares apaziguados e amenos (ainda que aldeões), em terras que, sabidamente, vivem em eterno conflito. A inverossimilhança é tamanha que toca as notas do absurdo. É dessa dissonância - aqui elevada à máxima potência - que a estrutura narrativa de $\mathrm{Oz}$ se nutre. Senão vejamos:

Beni Avni [...] ergueu o olhar para o quadronegro, onde estava escrito com a mesma caligrafia feminina: "Comparar a vida tranquila da aldeia com a ruidosa vida urbana - favor entregar até quartafeira, o mais tardar." Embaixo dessa inscrição viam-se as palavras: "Deve-se ler muito bem em casa os três próximos capítulos, e se preparar para responder a todas as perguntas de cor." $\mathrm{Na}$ parede estavam pendurados os retratos de Herzl, do presidente do Estado de Israel e do primeiroministro, assim como alguns cartazes ilustrados, num dos quais estava escrito: "Os amantes da natureza protegem as flores silvestres."

As carteiras amontoavam-se confusamente, como se os alunos as tivessem empurrado em sua arremetida para a saída ao primeiro toque da campainha. Nos parapeitos das janelas, os gerânios pareciam ressecados e maltratados. Diante da mesa do professor estava pendurado um grande mapa de Eretz Israel com um grosso círculo verde 
em torno da aldeia Tel Ilan, entre as montanhas da região de Menashé. [...] Beni Avni saiu da sala e, mancando um pouco, continuou a perambular por mais algum tempo pelos corredores vazios. Gotas de sangue pingavam de sua mão ferida e sinalizavam seu percurso. (OZ, 2009, p.128-129)

O que depreendemos do episódio acima pode ilustrar, de certa forma, o processo de construção e desmantelamento a que nos referimos anteriormente, quando buscamos nos ater às estratégias do narrar que aqui se apresentam. No pequeno ambiente escolar, que, idealizadamente, visa enaltecer a paisagem irretocável da aparente vida tranquila do campo, emoldurada no mapa estático fixado na parede, surge o homem que perambula, mancando pelos corredores e de cuja mão goteja o sangue a sinalizar-lhe o percurso.

O insólito, assim, se anuncia para criar a brusca ruptura com a placidez e a amenidade tão bem construídas previamente, como que para fazer estremecer o quadro paisagístico de Tel Ilan, trazendo-o abruptamente ao chão.

É dessa forma que, inevitavelmente, pouco a pouco, a aldeia de $\mathrm{Oz}$ vai sendo violada, ou por meio de estranhas escavações a solapar-lhe a base, ou de angustiantes esperas dos que insistem em não chegar, ou pela chegada insólita de hóspedes invasores, ou ainda por sombras de idílios de amores vãos.

Do ponto de vista procedimental, a cada novo episódio, o narrador em terceira pessoa, inicialmente reforça as características aldeãs de Tel llan, que assume a letargia e a fixidez de certos vilarejos interioranos, em que tudo se arrasta e as horas demoram a passar. Tal estratégia narrativa, na verdade, carrega nas tintas dessa paisagem irretocável, bucólica, provinciana para configurar 
a rotina de uma estabilidade quase palpável, em que nada parece sair dos eixos ou do lugar. Tem-se sempre a impressão de que não há espaço para o imprevisível, num lugar em que - aparentemente - tudo segue o ciclo natural da vida, sem grandes sobressaltos. Mas exatamente por não deixar nada entreaberto, pintando, por meio das descrições estáticas e, ao mesmo tempo, vigorosas da velha aldeia, um quadro em que as cores locais obedecem aos ditames autorreferentes de exuberância e normalidade, é que se prepara o caminho para o surpreendente. Melhor dizendo, por meio desse tipo de procedimento narrativo altamente irônico, a paisagem paradisíaca ancestral da aldeia, aos poucos, mostra seu avesso, revelando o que ali se esconde. E o expediente estilístico escolhido para tanto é a articulação de elementos estruturais que colaboram para construir o "insólito".

Vejamos como isso se verifica, por exemplo, no conto intitulado "Os que esperam". A descrição da aldeia, logo de saída, é minuciosa e exuberante:

Tel Ilan, uma aldeia antiga que já completara cem anos, era cercada de pomares e jardins frutíferos. Nos declives das colinas a leste estendiam-se vinhedos de uvas viníferas. Do outro lado da estrada, renque após renque, cresciam amendoeiras. Os telhados, com suas telhas vermelhas, estavam imersos no espesso verde das copas de velhas árvores. Muitos dos habitantes ainda se dedicavam à agricultura e tinham como ajudantes trabalhadores de fora, que moravam em cabanas nos fundos dos quintais. Mas alguns dos homens da aldeia já tinham arrendado suas propriedades e viviam de alugar quartos a visitantes, de galerias e butiques da moda, assim 
como de trabalho externo [...] E ao meio-dia de toda sexta-feira as ruas da aldeia se esvaziavam e todos os moradores se deitavam para descansar atrás de persianas cerradas. (OZ, 2009, p.113-114)

É dentro desse cenário que se nos apresenta o presidente do Conselho da aldeia, Beni Avni, um homem alto e magro, cujas roupas são um tanto quanto desleixadas, mas que tem um andar resoluto e uma expressão atenta e curiosa, como a dizer sempre: "Eu gosto de você e gostaria que me contasse mais sobre você mesmo" (OZ, 2009, p.114).

Aparentemente, Beni se mostra muito educado e cordato; alguém capaz de administrar a vida com sensatez e equilíbrio, além de tratar com o máximo respeito todos os que dele necessitam. Mas eis que, em meio aos dias sempre iguais, seguindo os mesmos hábitos rotineiros, recebe em seu escritório a visita de Adel, o jovem árabe que já aparecera no episódio anterior e que aqui surge apenas como portador do inusitado ${ }^{3}$. Com efeito, este vai à procura do conselheiro para lhe entregar um bilhete:

Adel hesitou um pouco, sentou na beira da cadeira sem se recostar, e disse:

- É o seguinte. Sua esposa me viu andando em direção ao centro e me disse para passar por aqui no caminho e lhe entregar uma coisa. Ou melhor, uma carta.

Beni Avni estendeu a mão e recebeu de Adel o bilhete.

- Onde você a encontrou?

3 Um expediente recorrente nos diversos episódios do livro é a aparição de um ou outro personagem já apresentados ao leitor, transitando por aqueles espaços narrativos, como se circulassem por entre as vielas da aldeia, tal qual fio condutor a alinhavar as partes do mesmo bordado, buscando obter a coesão entre um conto e outro. 
- Ao lado do Jardim da Recordação.

- Em que direção ela foi?

- Não foi. Ficou sentada num banco.

[...] Beni Avni abriu o bilhete dobrado e nele encontrou, na caligrafia redonda e serena de Naava, numa folha arrancada da caderneta da cozinha, as quatro palavras:

“Não se preocupe comigo." (OZ, 2009, p.115)

A anunciação do insólito, neste conto, é muito sutil. Fugindo da cena rotineira vivenciada pelo casal, a esposa apenas pede, por meio de um singelo bilhete, extremamente sucinto, que o marido não se preocupe com ela. Ponto e basta.

O que de início é apenas um mero aviso, conforme a narrativa avança, transforma-se em longo e angustiante ritual de busca e de espera. O espectro de Naava está em toda parte da casa, como se tivesse impregnado totalmente o ambiente, o ar da casa em que viviam. Para intensificar a ausência da mulher que, aos poucos se instaura, os detalhes são minuciosos e precisos, acentuando o ritmo de normalidade, de corriqueiro cotidiano, em que a aberração é a falta de Naava. A ênfase aos detalhes exacerba a morosidade característica desses espaços aldeões, em que o tempo parece se arrastar lento, tanto quanto os pêndulos de velhos relógios, que badalam as horas pesadamente. Mal comparando seria como se, habituadíssimos a ver o mesmo quadro na parede, por muito tempo, de repente e de modo surpreendente e absurdo, déssemos pela falta de um de seus elementos constituintes:

Em vão Beni Avni procurou um bilhete de Naava no lugar de sempre, sob o vaso, na sala. Mas sobre 
a mesa da cozinha esperava-o o seu almoço, um prato coberto com outro prato para que a comida não esfriasse: um quarto de frango, purê de batata, cenoura cozida e ervilha. À esquerda e à direita, uma faca e um garfo, e embaixo da faca um guardanapo dobrado. Beni Avni esquentou seu prato por dois minutos no micro-ondas, pois, apesar de estar coberta, a comida já esfriara um pouco. Enquanto isso tirou da geladeira uma garrafa de cerveja, que verteu num copo grosso. Depois se sentou para comer e comeu com voracidade, mas sem gosto, enquanto ouvia o rádio, que transmitia música leve com longos intervalos comerciais. Em um desses intervalos pareceu-lhe ter ouvido os passos de Naava no caminho de entrada da casa. Ele se levantou, foi até a janela da cozinha e olhou para fora durante muito tempo, mas o quintal estava deserto; entre os espinheiros e os trastes ali amontoados viamse apenas um varal de carroça desmontado e duas bicicletas enferrujadas. (OZ, 2009, p.118)

A angústia da falta se mistura ao mistério do paradeiro da mulher, cuja sombra continua a perambular pela mente de Beni, de modo quase tangível:

Beni Avni despiu a roupa de baixo, entrou no chuveiro, regulou a quentura da água e banhou-se demoradamente. Enquanto se banhava pensou ter ouvido a porta ranger. Assim, ainda se enxugando, ergueu a voz e chamou, Naava? Mas não houve resposta. (OZ, 2009, p.119)

Inconformado, ele vai ao estúdio onde ela costumava modelar figuras de barro de criaturas imaginárias. Procura pela esposa em cada ângulo, vão, fresta da casa, como um cego que tateia, à esmo, algum vestígio de presença. $\mathrm{O}$ que intensifica mais ainda a ruptura 
do inusitado desaparecimento é a ênfase dada pelo narrador a tudo que remete e lembra Naava, de modo a fazer com que ela continue ali, onipresente, mesmo sem o estar:

Dirigiu-se ao quarto para deitar e descansar. Junto à cama estavam os chinelos de Naava, pequenos, coloridos e um pouco gastos nos calcanhares, como dois barcos de brinquedo. Por quinze ou vinte minutos Beni ali ficou sem se mover, deitado de costas e com os olhos fixos no teto. (OZ, 2009, p.120)

Depois da primeira fase de surpresa e inércia que o tomam, resolve sair à procura dela e então tem início a longa perambulação pela escola em que lecionava, pelos lugares que costumava frequentar, pelos trajetos que os dois perfaziam juntos. A partir desse momento, a narrativa muda de rumo, saindo do detalhismo descritivo das cenas introdutórias, numa investida de tom mais memorialístico.

De modo gradual, enquanto empreende a incansável busca, a imagem bem constituída e aparentemente inabalável do Conselheiro passa a se decompor, de modo análogo à decomposição do cenário ideal de Tell Ilan, na cena da escola, descrita anteriormente.

A cada cena, retira-se um pouco daquela aura irretocável da cena inaugural, em que a aldeia resplandecia como o "lugar dos lugares", para afinal se reduzir ao inferno na terra. O que se anuncia é a ameaça subliminar que, num crescendo, vai tomando forma até atingir o estágio de total devastação e ruína, descrito de modo apocalíptico no último capítulo, qual bomba relógio que fosse sendo alimentada ao longo da narrativa para, no rito derradeiro, explodir: 
podridão se espalha entre nossas cabanas. Tudo que é de ferro oxida da noite para o dia, ervas peçonhentas derrubam as cercas, o bolor devora as paredes, a umidade faz a palha e o feno enegrecerem como carvão, mosquitos enxameiam por toda parte, nossos quartos estão cheios de insetos voadores e rastejantes. A própria poeira borbulha, pustulenta. Carunchos, traças e pulgões roem móveis, parapeitos de madeira e até telhas podres. O verão inteiro, nossas crianças padecem de furúnculos, eczemas e gangrenas. Os velhos morrem com as vias respiratórias decompostas. 0 odor fétido da morte exala também dos vivos. (OZ, 2009, p.176)

Era isso que se escondia por trás da amena Tel llan: arrancandoIhe as máscaras do fantástico, a realidade cruel e avassaladora escancara sua face mais verdadeira.

Para concluir, cabe lembrar o que propõe Andrè Jolles ao afirmar que "a narração fantástica não contradiz as leis do realismo literário, mas demonstra que tais leis se transformam em um irrealismo quando a atualidade é considerada como totalmente problemática" (Apud CESERANI, 2006, p.64).

Talvez isso explique por que nestas Cenas da vida na aldeia, Amós $\mathrm{Oz}$ não se filie à tradição das tendências fantásticas que lançam mão explicitamente do sobrenatural gótico ou fantasmagórico, mas explore ao máximo o que pode haver de inverossímil e inusitado nas contradições do próprio comportamento humano, fazendo irromper, ironicamente, o absurdo na mais absoluta banalidade cotidiana. 


\section{REFERÊNCIAS}

CALLOIS, Roger (1980). "Fantastique". Apud: CESERANI, Remo (2006). O fantástico. Curitiba: Editora UFPR. p.47.

CESERANI, Remo (2006). O Fantástico. Curitiba: Editora UFPR.

CURTIUS, Ernst Robert (1996). Literatura europeia e idade média latina. São Paulo: EDUSP \& HUCITEC. p. 254-258.

FREUD, Sygmund (1996). "Os chistes e sua relação com o inconsciente". Apud: ORLANDO, Francesco (2009). "Estatutos do sobrenatural na narrativa". In: MORETTI, Franco (Org.). A cultura do romance. São Paulo: Cosac Naify. p.245-281.

JOLLES, Andrè (1930). "Einfache formen: legende, sage, mythe". Apud: CESERANI, Remo (2006). O fantástico. Curitiba: Editora UFPR. p.64.

ORLANDO, Francesco (2009). "Estatutos do sobrenatural na narrativa". In: MORETTI, Franco (Org.). A cultura do romance. Trad: Denise Bottmann. São Paulo: Cosac Naify. p.245-281.

OZ, Amós (2009). Cenas da vida na aldeia. São Paulo: Cia das Letras.

TODOROV, Tzvetan (2008). Introdução à literatura fantástica. São Paulo: Perspectiva. 